\title{
SOME NOTES ON ORNITHOGALUM UMBELLATUM L. AND ORNITHOGALUM DIVERGENS BOR.
}

\author{
TH. W. J. GADELLA
}

Instituut voor Systematische Plantkunde, Utrecht

\section{SUMMARY}

Dutch material of Ornithogalum umbellatum $\mathrm{L}$. sensu lato was cytologically investigated. Two cytotypes appeared to occur, with the chromosome numbers $2 n=27$ and $2 n=54$. A description of the triploid and hexaploid plants is given. The triploids should be assigned to $O$. umbellatum, the hexaploids may be assigned provisionally to $O$. divergens Bor. The taxonomic status of the latter species is discussed. Further research is required for the solution of the taxonomic problems.

Ornithogalum umbellatum is a variable species, both in morphological and cytological respect. Cytological studies in Ornithogalum umbellatum L. sensu lato revealed that 6 cytotypes occur: $2 \mathrm{n}=18,27,36,45,54,72$ (NEVES 1952). In a previous paper (GADELLA 1970) I published the results of cytological studies of 19 plants from seven Dutch localities. All these plants turned out to be triploid $(2 n=27)$. They largely reproduce by vegetative means, i.c., by forming bulbils, whereas their fruits are usually empty. Two seeds could be harvested in 1970, but they did not germinate. Some new plants could be added to the collection. They originated from Walcheren (province of Zeeland) and from Sassenheim (province of Zuid-Holland). They were cytologically studied and proved to be hexaploid $(2 n=54)$. The triploid and hexaploid plants differ considerably from each other in morphological respect. They may be distinguished as follows (the descriptions are based on plants grown in pots):

\section{I. triploid plants:}

The bulbs form leaf-bearing bulbils. Very soon the bulbils and bulbs separate from each other but remain in very close proximity to each other. The leaves are linear, light green or green, $13-15 \mathrm{~cm}$ long and $2.5-3.5 \mathrm{~mm}$ wide. A conspicuous white stripe is visible on the upper side of the leaves. The inflorescence is narrow, few-flowered (3-5 flowers) and visible from the end of April onwards. The pedicels are ascending, the length of the lowermost pedicel being $3-3.5 \mathrm{~cm}$, the corresponding membranaceous bract $2.5-3 \mathrm{~cm}$. The outer tepals are $15 \mathrm{~mm}$ long and $5 \mathrm{~mm}$ wide, the filaments are 5-6 $\mathrm{mm}$ long. The fruits are capsular, blunt at the top, and provided with 6 prominent longitudinal ribs. The triploids flowered in 1971 during the second half of May (see fig. 1). 


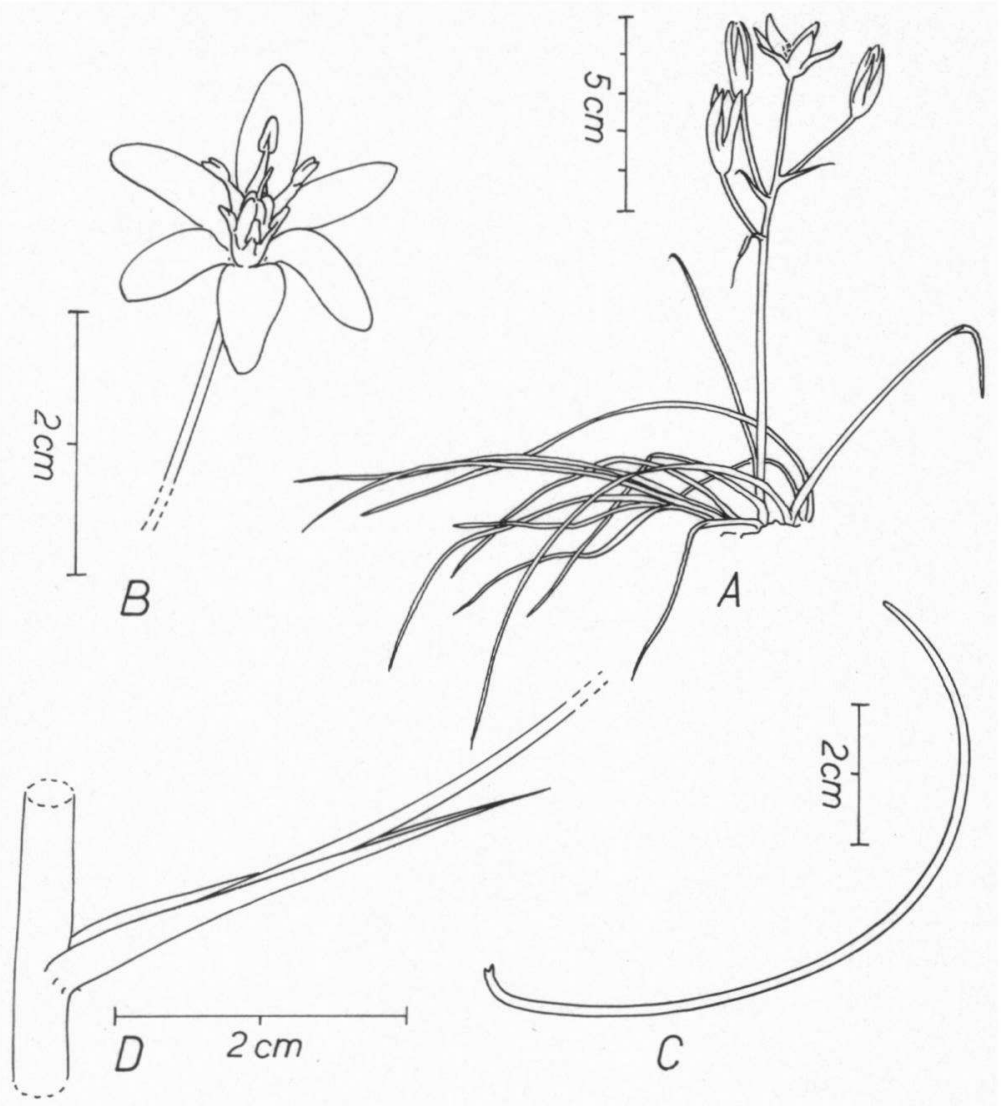

Fig. 1. Ornithogalum umbellatum $\mathbf{L}$.

A: Habit of the plant. The few-flowered inflorescence has flowers with ascending pedicels. B: the flower. C: the linear leaf. D: pedicel with bract of the lowermost flower.

\section{II. hexaploid plants:}

The bulbs form very few bulbils, which are externally invisible since they are covered by the tunica externa of the bulb. The bulbils lack leaves. The leaves are linear, $22-27 \mathrm{~cm}$ long, dark green and provided with a conspicuous linear white stripe on the upper side. The inflorescence is wide, contains 14-18 flowers, and is visible from the middle of March onwards. The pedicel of the lowermost flower is $6-7 \mathrm{~cm}$ long, the corresponding membranaceous bract $3.5-4.5 \mathrm{~cm}$ long. The outer tepals are c. $25 \mathrm{~mm}$ long and $7 \mathrm{~mm}$ wide. The filaments are 9-10 $\mathrm{mm}$ long. The fruits do not differ from those of the triploid plants. The hexaploid plants flowered during the second half of April and the first two weeks of May (fig. 2). 


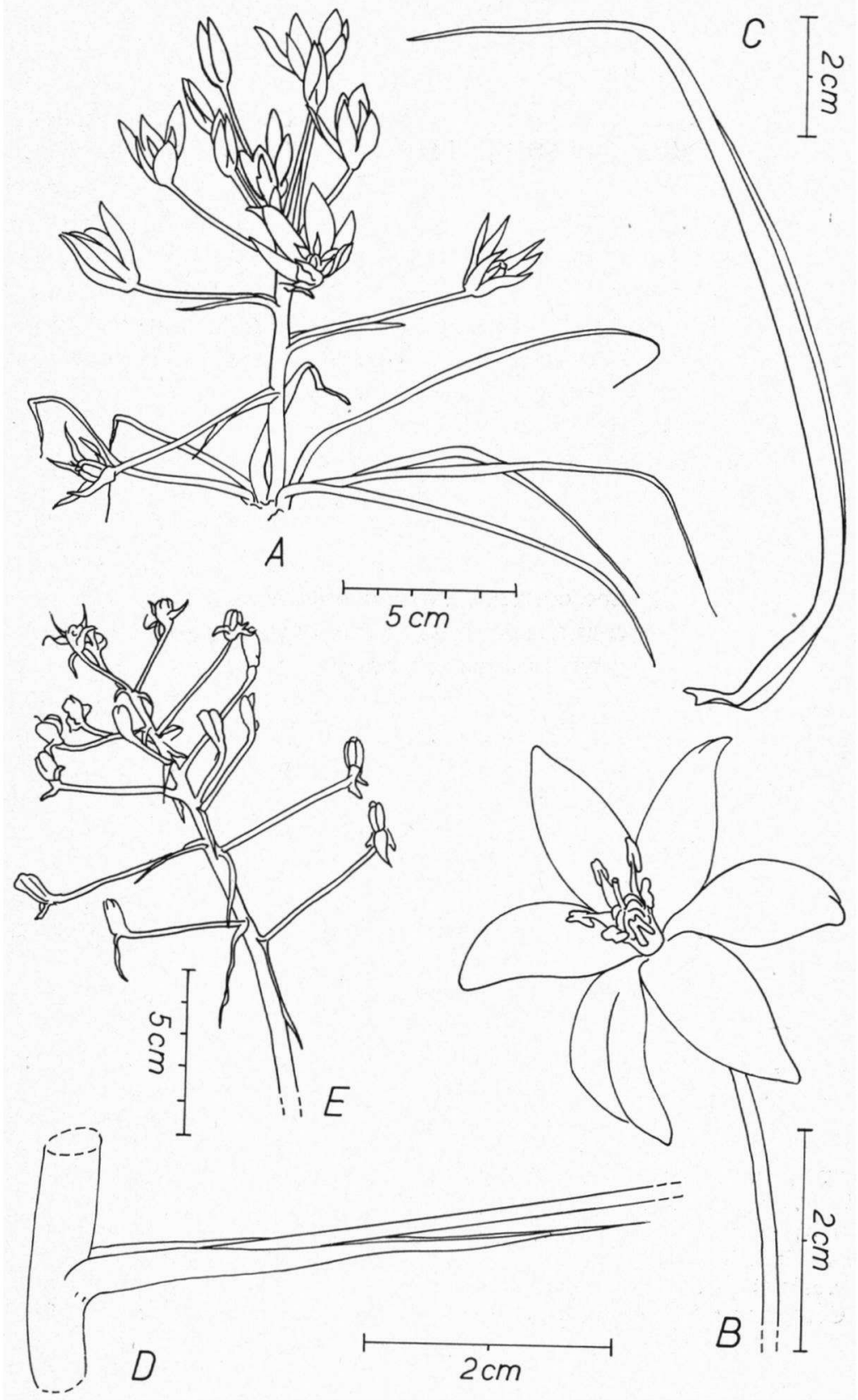

Fig. 2. Ornithogalum divergens Bor.

A: Habit of the plant. The pedicels form an angle of about $90^{\circ}$ with the main axis of the manyflowered inflorescence. B: the flower. C: the linear leaf. D: pedicel with bract of the lowermost flower. E: the inflorescence with fruits that are borne in an erect position. 
Using the key to the genera of the Scilleae and Chlorogaleae by BAKER (1872), the author arrived at the conclusion that the triploid plants belong to Ornithogalum umbellatum $\mathrm{L}$., the hexaploids to $O$. divergens Boreau.

FeINBRUN (1941) is of the opinion that $O$. divergens is a Mediterranean species, whereas $O$. umbellatum is distributed throughout Europe with the exception of some areas in northern Scandinavia and the East of Russia. $O$. divergens Bor. was not found earlier in the Netherlands (VAN Ooststroom \& ReICHGELT 1964). Therefore, the possibility should not be excluded that the hexaploid plants escaped from cultivation or were introduced into the Netherlands. At any rate, further research is required in order to arrive at more definite conclusions with regard to the constancy of the observed correlation between morphological and cytological characters.

Some authors regard $O$. divergens as a subspecies of $O$. umbellatum (i.a. ASCHERSON \& GRAEBNER 1905-1907): O. umbellatum L. subsp. divergens (Boreau) Aschrs. et Graebn.

The observed differences in geographical distribution seem to support this opinion, but the morphological differences (provided that they are constant throughout the range and correlated with cytological differences) are in favour of treating both cytotypes as species. The differences in flowering period seem to prevent crosses between triploids and hexaploids, at least under garden conditions. Also the differences in chromosome number may indicate that both cytotypes are reproductively isolated. This lends support to the opinion that $O$. umbellatum and $O$. divergens are two distinct species.

\section{ACKNOWLEDGMENT}

The author is much indebted to Mr. A. de Visser (St. Laurens) and to Mr. J. Wieffering for providing him with bulbs of hexaploid plants and to Mr. H. Rypkema for the drawings.

\section{REFERENCES}

AsCherson, P. \& P. GRAEBNER (1905-1907): Synopsis der mitteleuropäischen Flora 3: 238-257. (Leipzig).

BAKER, J. G. (1872): Revision of the genera and species of Scilleae and Chlorogaleae. J. Linn. Soc. Bot. 13: 209-292.

Feinbrun, N. (1941): The genus Ornithogalum in Palestine and neighbouring countries. Palest. Journ. Bot. 2: 132-150.

Gadella, TH. W. J. (1970): Enige aantekeningen betreffende Ornithogalum umbellatum L. Gorteria 5: 18-19.

NeVES, J. B. (1952): Estudos cariólogicos no género Ornithogalum L. Bol. Soc. Brot. 26: 5-192. Van Ooststroom, S. J. \& Th. Reichgelt (1964). Flora Neerlandica I, 6: 125-126. 